\title{
The effect of introducing guidelines for cervical spine radiographs in the accident and emergency department
}

\author{
S Maurice, S Brown, C Robertson, I Beggs
}

\begin{abstract}
Objective-To assess the effect of guidelines for $x$ ray requests on requests for cervical spine $x$ rays.

Setting-Accident and emergency (A\&E) department of tertiary referral centre.

Methods-Guidelines for all $x$ ray requests were introduced in the (A\&E) department of the Royal Infirmary of Edinburgh in February 1992. The effect of the guidelines on requests for cervical spine $x$ rays was assessed by retrospective review of all such $x$ rays taken over two 30 d periods, before and after the introduction of the guidelines. Junior staff had been in post for 3 months during both periods assessed. Films were reviewed for quality by a consultant radiologist.

Results-Guidelines reduced the number of inappropriate requests significantly; however, $26 \%$ of requests were still unnecessary. The standard of radiography improved but $49 \%$ of $x$ rays remained inadequate, usually because the C7/T1 level was not demonstrated on the lateral view. The A\&E doctors correctly interpretated the radiographs in $95 \%$ of examinations.
\end{abstract}

Conclusions-Guidelines reduce inappropriate $x$ ray requests. Further improvements can be expected with continued education.

( $f$ Accid Emerg Med 1996;13:38-40)

Key terms: cervical spine radiographs; accident and emergency department; guidelines.

A large number of radiographs are taken in accident and emergency (A\&E) departments, involving considerable time, cost, and radiation exposure. The radiographs taken in our department are subsequently reported by a radiologist. The appropriateness of requests and the quality of the films produced has been questioned. ${ }^{12}$ In an attempt to address these problems, guidelines for all radiological requests were produced jointly by the A\&E and Radiological consultants at the Royal Infirmary of Edinburgh and implemented in February $1992 .^{3}$ The guidelines took into account the recommendations of the Royal College of Radiologists. ${ }^{4}$

The aim of the guidelines was to assist the $A \& E$ doctors in their requests for radiographs rather than to lay down inflexible rules, and to specify for the radiographers the appropriate views to perform.
Indications for cervical spine radiographs include: patients in coma following head injury ${ }^{5}$; patients with neurological signs or symptoms of root or cord injury; patients with pain or symptoms referable to the neck following trauma or suspicion of cervical spine injury.

Patients with neck pain but no history of trauma do not normally need an $x$ ray. An adequate cervical spine series consists of anteroposterior (AP) and lateral views of the cervical spine and an open mouth view of the odontoid peg. ${ }^{6}$ The $\mathrm{C} 7 / \mathrm{T} 1$ interspace must be clearly visible on the lateral view. This may require the doctor to pull the patient's arms during the radiograph or to request a "swimmers" view.

We assessed: (1) the effect of guidelines on the number of examinations; (2) the appropriateness of requests; (3) the adequacy of the radiographic examination; (4) the $A \& E$ doctors' film interpretation.

\section{Methods}

We retrospectively reviewed all cervical spine radiographs taken over two 30 day periods. A preguideline group in November 1991 was compared with a postguideline group in May 1992. Junior staff had been in post for three months during both periods assessed. The records for all patients were reviewed to establish the indication for the examination, and the $A \& E$ doctors' interpretation.

The films were reviewed for adequacy and formally rereported by a consultant radiologist (IB).

Results

There was a significant reduction in the number of cervical spine radiographs performed in the $A \& E$ department following the introduction of guidelines.

In November 1991 (before the guidelines), 196 cervical spine $x$ rays were requested out of a total of $3800 x$ rays $(5 \cdot 1 \%)$. In May 1992 , after the introduction of the guidelines, 103 cervical spine radiographs were requested out of a total of $3520(2.9 \%)$. The reduction is highly statistically significant $(P<0.001$ by the Yates $\chi^{2}$ test) (table 1 ).

Table 1 Number of cervical spine $x$ ray requests

\begin{tabular}{lll}
\hline & $\begin{array}{l}\text { No of } C \text { spine } \\
\text { x rays requested } \\
\text { (total No x rays) }\end{array}$ & $\begin{array}{l}\text { \% of total } \\
\text { r rays }\end{array}$ \\
\hline November 1991 & $196(3800)$ & $5 \cdot 1$ \\
May 1992 & $103(3520)$ & $2 \cdot 9$ \\
& & $\mathrm{P}<0.001$
\end{tabular}


Table 2 Indications for $x$ ray

\begin{tabular}{lllll}
\hline & Coma after head injury & Neurological signs & Neck symptoms & No indication \\
\hline Nov 1991 & $14(7 \%)$ & $13(7 \%)$ & $102(52 \%)$ & $75(38 \%)$ \\
May 1992 & $12(11 \%)$ & $4(4 \%)$ & $65(63 \%)$ & $27(26 \%)$ \\
& & & & $P<0.05$ \\
\hline
\end{tabular}

Case mix comparability was ensured by taking a $10 \%$ sample of all patients presenting to the A\&E department in the two months. This was perfomed by looking at the first, 15th, and 30th day of each month. In November 1991,23 of the total of 640 patients $(3.5 \%)$ presenting in the three days had possible neck symptoms. In May 1992, 25 out of the total 702 patients $(3.56 \%)$ had possible neck symptoms. There is thus close case mix comparability.

The commonest indication for requesting cervical spine $x$ rays was neck pain or symptoms referable to the neck following trauma, accounting for $52 \%$ of the preguideline group and $63 \%$ of the postguideline group. Several patients had more than one indication.

In the preguideline group 75 patients $(38 \%)$ had no indication for cervical spine radiograph, that is, they did not meet any of the guideline indications and had a full range of pain free neck movement with no neurological abnormality. ${ }^{7}$

In the postguideline group 27 patients $(26 \%)$ had no indication for $x$ ray. This fall in unnecessary requests of $12 \%$ is statistically significant $(P<0.05)$ (table 2$)$.

Over $70 \%$ of the radiographs taken in the two periods were located. Of the $30 \%$ not located there were similar numbers of films missing from both November $(28 \%)$ and May $(34 \%)$. The radiographs were assessed in the following ways: (1) Had all three views been taken? (2) Was each of the three views complete? (3) Had each $x$ ray been labelled with the correct name, date, and side marker? For the radiographs to be adequate, all the criteria had to be met.

Before guidelines were introduced, two $(1.4 \%)$ of the examinations fulfilled all the criteria for adequacy. This low figure is because in 82 cases $(57 \%)$ only a lateral radiograph was taken, in 58 cases $(41 \%)$ lateral and AP views were taken, but in only three cases $(2 \%)$ were all three views taken. Following guidelines, 35 $(50.7 \%)$ were considered adequate $(P \ll 0.001)$ (table 3).

The standard of $x$ rays taken in the postguideline group was reviewed in more detail. Every patient had a lateral view, $78 \%$ an odontoid peg view, and $87 \%$ an anteroposterior view. Sixty nine per cent of the lateral views were adequate. Failure to show $\mathrm{C} 7 / \mathrm{T} 1$ occurred in $31 \%$ of lateral views. The C6/7 interspace was not visible in $20 \%$. The odontoid peg view was adequate in $87 \%$ of

Table 3 Standard of $x$ rays

\begin{tabular}{lcr}
\hline & Adequate & \multicolumn{1}{c}{ Inadequate } \\
\hline November 1991 & $2(1 \cdot 4 \%)$ & $141(98 \cdot 6 \%)$ \\
May 1992 & $35(50 \cdot 7 \%)$ & $34(49 \cdot 3 \%)$ \\
& $\mathrm{P} \ll 0 \cdot 001$ & \\
\hline
\end{tabular}

Table 4 Adequacy of $x$ rays in May 1992 (after introduction of guidelines)

\begin{tabular}{lll}
\hline & Performed & Adequate \\
\hline Lateral & $69(100 \%)$ & $48(69 \%)$ \\
Odontoid peg & $54(78 \%)$ & $47(87 \%)$ \\
AP & $60(87 \%)$ & $59(98 \%)$ \\
\hline
\end{tabular}

cases. Teeth obscuring the peg was the most common cause of inadequacy. Ninety eight per cent of the AP views were acceptable. In all cases, $x$ rays were labelled correctly (table 4).

All radiographs were reported by a consultant radiologist (IB) and compared with the A\&E doctors' interpretation. In both preand postguideline groups, the junior doctors showed over $95 \%$ accuracy in interpretation. Seven radiographs were interpreted incorrectly by the A\&E doctors. In four cases, a normal $x$ ray was thought to show an avulsion fracture of a vertebral body. Three abnormal films were reported as "normal" by the $A \& E$ doctors. The abnormalities were: (1) widened distance between the posterior arches of $\mathrm{Cl}$ and $\mathrm{C} 2$ suggesting possible ligamentous injury; (2) malalignment between C2 and C3 consistent with rotary subluxation; further views were normal; (3) a vertical lucency in the superior articular facet/pedicle of C3.

\section{Discussion}

The introduction of joint guidelines has been effective in reducing inappropriate requests for cervical spine $x$ rays by $12 \%$. The close case mix comparability provides strong evidence that the reduction in $x$ ray requests was a result of the guidelines. However, $26 \%$ of requests are still unnecessary. In our department this means 300 unnecessary requests per year. The large number of inappropriate requests may reflect junior doctors' anxiety over missing neck injuries. However, a normal radiograph could give the doctor a false sense of security. A previous study has shown that in $17 \%$ of patients with spinal cord injury, there was no plain film evidence of trauma. ${ }^{8}$ The importance of careful clinical examination in conjunction with appropriate radiography cannot be over stressed. ${ }^{9-11}$

The effectiveness of guidelines in reducing unnecessary requests has cost implications. A series of three cervical spine views costs approximately $£ 10.00$. The reduction in cervical spine $x$ ray requests resulted in an annual saving to this department of over $£ 11000$. The reduction in $x$ ray requests also reduces radiation exposure, and time spent in the $A \& E$ department.

Although guidelines resulted in improved radiographic quality, $49 \%$ of $x$ rays were still inadequate, mostly because the $\mathrm{C} 7 / \mathrm{T} 1$ interspace is not shown. ${ }^{12}$

The 95\% accuracy in A\&E doctors' radiographic interpretation could be misleading. ${ }^{13}$ As the incidence of abnormal films was very low $(<2 \%)$ we cannot conclude that junior doctors would show $95 \%$ accuracy in detecting plain film abnormalities. A previous study showed that A\&E senior house officers failed 
to recognise $78 \%$ of radiologically demonstable injuries of the cervical spine. ${ }^{14}$

Following this study, we are considering further methods to reduce inappropriate requests and to improve the standard of films as described below. ${ }^{15}$

We plan to hold monthly meetings in the A\&E department led by a consultant radiologist (IB) at which $x$ ray errors are discussed. This is an ideal platform at which to reinforce the guidelines, both with regard to indications for performing radiographs and to obtaining adequate films. It is important to stress the requirement for obtaining adequate views, and this is the joint responsibility of both radiographer and clinician.

All radiographs requested and performed in the $A \& E$ department are subsequently reported by a radiologist, and the reports matched with the record sheet. In future we intend to routinely incorporate into the report comments as to the appropriateness of the request and the adequacy of the films produced.

With continued education and the application of such guidelines we anticipate further improvements in the use and value of standard radiography in the $A \& E$ department.

We thank Mrs Carol Sinclair and Mrs Audrey Deuchars for typing the manuscript.
1 Moulton C, Griffiths PD. The adequacy of cervical spine radiographs in the A\&E department. $\mathcal{F} R$ Soc Med 1993;86:141-3.

2 Kreipke DL, Gillespie KR, McCarthy MC, Mail JT, Lappas JC, Broadie TA. Reliability of indications fo cervical spine films in trauma patients. $\mathcal{F}$ Trauma 1989 29:1438-9.

3 De Lacey G. Radiology guidelines in the accident department. Br $\mathscr{f}$ Hosp Med 1991;45:259.

4 Royal College of Radiologists. Making the best use of a department of radiology. Guidelines for doctors. London: RCR, 1989.

5 Hills MW, Deanes SA. Head injury and facial injury: is there an increased risk of cervical spine injury? $\mathcal{f}$ Trauma 1993;34:549-53; discussion 553-4.

6 Nicholson DA, Driscoll P. ABC of emergency radiology. London: BMJ Publishing Group, 1995.

7 Roth BJ, Martin RR, Foley K, Barcia PJ, Kennedy P. Roentgenographic evaluation of the cervical spine. A selective approach. Arch Surg 1994;129:643-5.

8 Riggins R The risk of neurological damage with fractures of the vertebrae. Trauma 1977;17:126-33.

9 Touquet R, Driscoll P, Nocholson D. Teaching in accident and emergency medicine: 10 commandments of accident and emergency medicine: 10 commandments of

10 Daffner RH. Cervical radiography in the emergency department: who, when, how extensive? $f$ Emerg Med 1993;11:619-20.

11 Ross SE, O'Malley KF, De Long WG, Born CT Schwab CW. Clinical predictors of unstable cervica spinal injury in multiply injured patients. Injury 1992;23: 317-9.

12 Davis JW, Phreaner DL, Hoyt DB, Mackersie RC. The etiology of missed cervical spine injuries. F Trauma 1993;34:342-6.

13 Vincent CA, Driscoll PA, Audley RJ, Grant DS. Accuracy of detection of radiographic abnormalities by junior doctors. Arch Emerg Med 1988;5:101-9.

14 Annis JAD, Finlay DBL, Allen MJ, Barnes MR. A review of cervical spine radiographs in casualty patients. $\mathrm{Br} f$ Radiol 1987;60:1059-61.

15 McNally E, De Lacey G, Lovell P, Welch T. (1995) Poster for accident departments: simple method of sustaining reduction in $\mathrm{x}$ ray examinations. $B M \mp 1995 ; 310: 640-2$. 